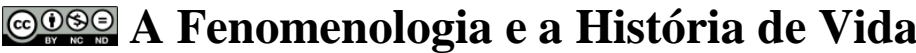

\author{
Paulo Roberto Brancatti * \\ Renata Portela Rinaldi ${ }^{* *}$
}

\begin{abstract}
Resumo: A fenomenologia é uma corrente filosófica, caracterizada pelo estudo aprofundado de um determinado fenômeno, pois, a priori, o que se apresenta à mente das pessoas, vem em forma difusa ou em forma de aparência. Compreendendo-a em uma perspectiva que prioriza o ser-nomundo, contextualizado com sua história, cultura, linguagem e movimento humano. Em vista disso, o presente artigo pretende compreender o entrecruzamento da fenomenologia e do método de História de vida, com intuito de vislumbrar a contribuições para o processo educacional e suas nuances pelas ciências de forma dialética com as contradições do sujeito em relação a sua formação acadêmica.
\end{abstract}

Palavras-chave: Fenomenologia. História de vida. Formação de professor.

\section{Phenomenology and the history of life}

Abstract: Phenomenology is a philosophical current, characterized by the depth study of a certain phenomenon, because, mainly, what appears to people's mind, comes in a diffuse form or in the form of appearance. Comprehending it in a perspective that prioritizes the being-in-the-world, contextualized with its history, culture, language and human movement. Because of it, this article intends to understand the intertwining of the

\footnotetext{
* Doutor em Educação pela Universidade Estadual Paulista Júlio de Mesquita Filho (UNESP). Professor na Universidade Estadual Paulista Júlio de Mesquita Filho (UNESP). E-mail: paulo.brancatti@unesp.br. ORCID: https://orcid.org/0000-0002-7260-8213

** Doutora em Educação pela Universidade Federal de São Carlos (UFSCAR). Professora na Faculdade de Ciências e Tecnologia (FCT/UNESP). E-mail: analuzia@fct.unesp.br. ORCID: https://orcid.org/0000-0001-7772-6705.
} 
phenomenology and the method of Life history, with the intention of gleaming contributions to the educational process and its nuances by the sciences in dialectical form with the contradictions of the subject in relation to his academic formation.

Keywords: Phenomenology. Life's history. Teacher training.

\section{La fenomenología y la historia de vida}

Resumen: La fenomenología es una corriente filosófica, caracterizada por el estudio profundo de un determinado fenómeno, ya que, principalmente, lo que parece a la mente de las personas, se presenta en forma difusa o en forma de apariencia. Comprenderlo en una perspectiva que prioriza el ser en el mundo, contextualizado con su historia, cultura, lenguaje y movimiento humano. Por ello, este artículo pretende comprender el entrelazamiento de la fenomenología y el método de la historia de la vida, con la intención de aportar contribuciones al proceso educativo y sus matices de las ciencias en forma dialéctica con las contradicciones del tema en relación con su formación académica.

Palabras clave: Fenomenología. La historia de la vida. Formación del profesorado.

\section{Introdução}

O presente artigo, com base na perspectiva teórica de MerleauPonty (1994), pretende compreender o entrecruzamento da fenomenologia na área da educação e o método de História de vida, como forma de subsidiar a formação acadêmica a partir da consciência do ser-no-mundo, construído historicamente e transformado pela sua linguagem cultural.

Etimologicamente a fenomenologia é o estudo ou a ciência do fenômeno: um método filosófico que desvela a cotidianidade do mundo vivido, onde a experiência se passa e transparece na descrição das vivências. O fundamental nesta corrente está centrado no estudo do 
fenômeno e na sua descrição, daquilo que aparece à consciência e que procura explorá-lo para atribuir um significado. Assim, essa abordagem filosófica pretende mostrar que o mundo, a priori, é o fenômeno, do que se mostra, do que se apresenta, e que precisa ser desvelado. Busca chegar ao fenômeno, revelar seu sentido, superar as aparências para chegar àquilo que realmente é, ou seja, a vivência em seu mundo vivido, numa experiência que lhe é própria, permitindo-lhe questionar o fenômeno que deseja compreender e buscar superar o que foi apreendido pela percepção humana, atribuindo um novo significado (DARTIGUES, 2005; MERLEAU-PONTY, 1994).

Nesse sentido, a fenomenologia proporciona o saber e a compreensão fundamentada no rigor filosófico, pois procura valorizar o ser na sua singularidade, uma vez que se preocupa com o que se repete e com o que se manifesta.

A contribuição da fenomenologia está presente, através da nova abordagem, na renovação dos métodos e no encaminhamento dos problemas nas ciências humanas, de forma notável nas ciências sociais como a psicologia, a psiquiatria, a biologia e na reorientação dos estudos de teologia, antropologia filosófica, filosofia da história, filosofia da linguagem, lógica e estética (OLIVEIRA; LOPES; DINIZ, 2008, p. 256).

Esse método filosófico desvela o cotidiano do mundo do ser, em que a experiência acontece, e, transparece na descrição de suas vivências. A fenomenologia é uma orientação ao novo modelo de pensamento no qual submeteu a concepção positivista a uma crítica radical. O termo fenomenologia significa o estudo dos fenômenos, daquilo que aparece à consciência, buscando conhecê-lo e explorá-lo, tornando-os claros, dando novos significados.

E, pensando na fenomenologia como uma corrente filosófica que prioriza o ser-no-mundo, contextualizado com sua história, com sua cultura, com sua linguagem e movimento humano, propomos neste texto, 
entender como a fenomenologia contribui para o processo educacional e suas nuances pelas ciências de forma dialética com as contradições do sujeito em relação a sua formação acadêmica.

Transpondo esses conceitos fenomenológicos à área da educação, pode-se afirmar que acerca de várias pesquisas sobre formação de professores, apoiando-se num estudo em que as práticas docentes, seus saberes, suas opiniões e suas representações decorrem de um período não muito distante, ou seja, mais precisamente a partir dos anos 1980 e 1990 do século XX. Essas investigações sobre a formação de professores, os estudos e diversas pesquisas passam a buscar novas referências para entender os desafios emergentes da sociedade atual em consonância ao fortalecimento da ideia de que o professor pode ser um sujeito consciente de suas práticas na busca pela transformação do ambiente de atuação profissional (ANDRÉ, 2010; QUEIROZ, 1987; TARDIF, 2012).

Ao considerar a educação como um fenômeno, devemos começar por reconhecer que se trata de uma experiência profundamente humana, num sentido mais amplo de uma experiência universal, já que todos os homens se educam (KANT, 1999). Isso significa que a experiência da educação sendo uma das manifestações mais primitivas e típicas do ser humano, em relação ao desenvolvimento dos indivíduos, como também os grupos sociais, a família e a sociedade. Por isso, a história, os fatos, os acontecimentos, as vivências, estão implícitos na estrutura do fenômeno educacional (BRANDÃO, 1988).

Isto quer dizer que, em sua polissemia, a educação pode ser enfocada de vários pontos de vista, mas cada um deles acaba por nos remeter aos demais. E, na medida em que, por qualquer motivo, os autores privilegiam algum aspecto em detrimento dos outros, eles incorrem num reducionismo que tanto impede a compreensão do fenômeno educacional como de fenômeno humano propriamente dito (REZENDE, 1990, p. 46). 
Nesse sentido, a investigação interpretativa, indagação narrativa e trajetória de vida se desenvolveram e se difundiram com relativa amplitude e de legitimidade na teoria social e educativa desde a década dos anos de 1980 no Brasil e em outros países do mundo. Disso resulta que pesquisador e pesquisado têm oportunidades para refletir, aprender e ressignificar-se no próprio processo de coleta e análise dos dados através dos instrumentos metodológicos de observação e entrevista, na construção de novos conhecimentos produzidos na investigação (FREITAS; SOUSA; KRAMER, 2003).

Assim, as investigações interpretativas e narrativas em educação são, em grande parte, herdadas da linha hermenêutico-fenomenológica na qual os sujeitos transformam-se em atores de seus discursos, de suas ações, de suas interações, de suas crenças e, por isso, passam a ser motivos de investigação do ato educativo na área da formação de professor, com propósito de fundamentar a área de formação acadêmica (SUÁREZ, 2008).

Admite-se que esses atores são construtores de sua vida, de seu tempo, de sua história e de suas crenças. Portanto, ao permitir que os professores em sua prática cotidiana possam expressar seus pensamentos e ações, nos remete a compreender o objeto da História de Vida encontrada nos relatos das experiências que dão novos significados ao mundo vivido, como afirma Rezende (1990), apropriando-se do pensamento de MerleauPonty: "[...] tudo quanto sabemos sobre o homem e sobre o mundo, graças à contribuição das ciências, deve ser posto entre parênteses, para que possamos redescobrir a experiência primitiva em toda sua riqueza." (REZENDE, 1990 apud MERLEAU-PONTY, 1994, p. 36).

$\mathrm{Na}$ busca de compreender a raiz epistemológica da História de Vida pode se afirmar que a mesma se encontra ancorada na corrente filosófica da Fenomenologia, compreendida a partir da percepção de Merleau-Ponty (1994), que propõe uma nova leitura a partir da intencionalidade, subjetividade e sensibilidade, que se concretiza na motricidade, corporeidade e linguagem.

Alguns pontos relevantes precisam ser considerados, ou seja, o conceito de mundo, da ciência e da experiência: 
Tudo aquilo que sai do mundo, mesmo para ciência, eu sei a partir de uma visão de mundo ou de uma experiência do mundo sem a qual os símbolos da ciência não poderiam dizer nada. Todo o universo da ciência é construído sobre o mundo vivido, e se queremos pensar a própria ciência com rigor, apreciar exatamente seu sentido e seu alcance, precisamos primeiramente despertar essa experiência do mundo da qual ela é a expressão segunda. (MERLEAUPONTY, 1994, p. 3).

Merleau-Ponty na obra A Fenomenologia da Percepção, no seu prefácio apresenta uma reflexão do sujeito e sua relação com a consciência distinguindo-se aquilo que a ciência define como natural em relação aquilo que envolve a ação humana. E dessa maneira, ele assim descreve:

Eu não sou um 'ser vivo' ou mesmo um 'homem' ou mesmo 'uma consciência', com todos os caracteres que a zoologia, a anatomia social ou a psicologia indutiva reconhecem a esses produtos da natureza ou da história - eu sou a fonte absoluta; minha experiência não provém de meus antecedentes, de meu ambiente físico e social, ela caminha em direção a eles e os sustenta, pois sou eu quem faz ser para mim (sentido das palavras e linguagens) essa tradução que escolho retomar, ou este horizonte cuja distância em relação a mim desmoronaria, visto que ela não lhe pertence como uma propriedade, se eu não estivesse lá para percorrê-la com o olhar. (MERLEAUPONTY, 1994, p. 3-4).

O mundo não é aquilo que eu penso, mas aquilo que eu vivo e vivencio; estou aberto ao mundo, convivo-me indubitavelmente com ele, mas não o possuo, porque ele é inesgotável. Segundo Merleau-Ponty (1994, p.14), “[...] há um mundo, ou, antes, há o mundo que se funda numa relação de existência, entre aquilo que se forma e aquilo que se apresenta com intencionalidade". Por isso, para a fenomenologia, toda consciência é consciência de algo. 
Trata-se de reconhecer a própria consciência como projeto do mundo, destinada a um mundo que ela não abarca nem possui, mas em direção a qual não cessa de se dirigir - e o mundo como este indivíduo préobjetivo cuja unidade imperiosa prescreve à consciência a sua meta. (MERLEAU-PONTY, 1994, p. 15-16).

$\mathrm{Na}$ sequência do raciocínio de Merleau-Ponty aparece o que ele denomina de Noções de Intencionalidade, onde ele propõe superar a visão clássica de naturezas verdadeiras e imutáveis para uma visão da fenomenologia da gênese, que funda se em mutações constantes,

Quer se trate de uma coisa percebida, de um acontecimento ou de uma doutrina, 'compreender' e reapropriar-se da interação total (não apenas aquilo que são para a representação - as propriedades da coisa percebida, a poeira dos fatos históricos, as ideias introduzidas pela doutrina), mas a maneira única de existir que se exprime na ideia que se forma à natureza. Trata-se de reencontrar a ideia no sentido Hegeliano de história numa certa maneira de entender as manifestações do mundo a partir do historiador que consegue assumir e retomar as dimensões da história, ou seja, não há uma palavra, um gesto humano, que não tenham uma significação. (MERLEAU-PONTY, 1994, p. 16-17).

\section{A subjetividade fenomenológica}

Em Merleau-Ponty (1994), encontra-se uma primeira ideia de subjetividade que compreende a filosofia da existência e da linguagem, em sua condição de ser situado no mundo-da-vida (Lebenswelt). O mais importante para o sujeito é a busca pelo sentido para sua vida e isto, contudo, depende do seu termo de como ele mesmo esclarece sobre a natureza, a história, o mundo e o ser. Desse modo a analítica existencial de Merleau-Ponty, sobre a experiência do outro e da subjetividade, se faz a 
partir do seu ser no mundo, isto é, no contexto histórico, social, cultural e psicológico, no ambiente em que o sujeito vive e constrói sua realidade.

Essa expressão ser-no-mundo, utilizada várias vezes na obra da Fenomenologia da Percepção, nos remete ao pensamento social e concreto do ser humano enquanto sujeito inserido numa práxis em que os sentidos, as experiências e as intersecções acontecem pelas experiências do outro, pela engrenagem de umas nas outras. Ele é, portanto, inseparável da subjetividade e da intersubjetividade que formam sua unidade pela retomada de minhas experiências passadas em minhas experiências presentes, junto com experiências dos outros em relação a minha, de forma dialeticamente construída (MERLEAU-PONTY, 1994, p. 18).

O sujeito é percebido, então, em sua singularidade, mas situado em sua relação concreta no contexto histórico, social e cultural. Nesse raciocínio, numa pesquisa qualitativa de representação subjetiva, a cultura torna-se elemento fundamental e portador de um significado que deve ser resgatado pela interpretação e descrição da realidade (FREITAS; SOUSA; KRAMER, 2003).

Por meio da fenomenologia da existência se compreende a historicidade do ser humano, articulada às noções de intencionalidade: "Nós tomamos em nossas mãos o nosso destino, tornamo-nos responsáveis, pela reflexão, por nossa história, mas também graças a uma decisão em que empenhamos nossa vida, e nos dois casos trata-se de um ato violento que se verifica exercendo-se" (MERLEAU-PONTY, 1994, p. 19).

A estrutura do fenômeno implica uma determinada concepção de homem e de mundo, ampliando uma visão antropológica inseparável de uma cosmologia onde o homem não é mundo e nem o mundo é o homem, mas um não se concebe sem o outro. Nesse sentido, a presença da dialética é fundamental para entender a estrutura fenomenal. De outra forma, tanto o homem como o mundo continua sendo percebido, cada um qual a seu modo, como uma estrutura, e, no dizer de Merleau-Ponty, o fenômeno é na verdade, uma estrutura de estruturas (REZENDE, 1990). 
O ser no mundo compreende também a experiência que cada sujeito tem ao longo de sua vida e de como esse mundo é vivido. A volta às próprias raízes, a redescoberta do mundo vivido é condição radical para o nascimento da reflexão, mesmo sendo das ciências, que quando aparecem, num mundo já constituído. Por isso, a fenomenologia valoriza a experiência como condição para interagir e dialogar com os vários tipos de conhecimentos científicos, discutindo, criticando e integrando suas diversas contribuições (REZENDE, 1990 apud MERLEAU-PONTY, 1994).

Para Merleau-Ponty (1994, p. 14), “o mundo é não aquilo que eu penso, mas aquilo que eu vivo; eu estou aberto ao mundo, comunico-me indubitavelmente com ele, mas não o possuo, ele é inesgotável”. Com esse raciocínio, chega-se à noção de intencionalidade, como descoberta principal da fenomenologia. $\mathrm{O}$ autor volta sua análise ao pensamento de Kant e de Husserl para afirmar que "[...] toda consciência é consciência de algo" para explicar a intencionalidade existente entre o sujeito e o objeto intermediado pelo conhecimento e identificada pela experiência do mundo vivido.

Em relação ao sujeito concreto, a fenomenologia assume a visão de corpo-próprio, ou seja, o corpo-sujeito, não como visão dualística, mas numa visão dialética de concretude de sua existência. Nesse sentido,

A condição humana é corporal, mas o corpo integra uma estrutura propriamente humana, na qual o sentido que a unifica não se reduz ao das formas inferiores, sincréticas ou amovíveis, mas se plenifica como forma simbólica. O comportamento humano é uma capacidade típica do mundo humano, caracterizado, precisamente, pelo aparecimento da forma simbólica e sua capacidade de estruturar as demais. (REZENDE, 1990, p. 38).

Nossas experiências originais são fundamentais para que nossa compreensão de mundo seja significativa, ou seja, a relação que se dá com o mundo, se completa pelos movimentos, que definem as pessoas com suas 
marcas e modos de movimentar-se e significar-se nesse mundo. Desse modo, a educação como um caminho em ebulição que congrega pessoas das mais variadas formas de pensar, conhecer, agir e transformar o ambiente, seja capaz de elevar o ser humano emancipado, crítico e livre, a sua verdadeira condição de conhecer o mundo vivido (CUNHA et al., 2018).

Nossa realidade é constituída por sujeitos, que através da relação com mundo, tornam-se atores dos seus próprios movimentos, permitindo com suas experiências, conceituar suas ações para compreender o movimento humano em suas interfaces subjetivas. E, por isso, a inserção, a concretude, as atitudes, os gestos, os sentidos, dão resultados significativos quando o sujeito pode agir em seu mundo e em suas ações pedagógicas.

As pesquisas que utilizam a metodologia da História de Vida para estudar fenômenos educacionais, aproximam-se da fenomenologia para terem maior compreensão dos significados e das ações dos atores no seu mundo cotidiano que fundamentam a abordagem qualitativa desses atores.

\section{História de vida: algumas considerações}

Entendemos que há vários meios de se conhecer uma realidade, seja informalmente ou com intuito de uma investigação cientifica e acadêmica. Um dos métodos utilizados atualmente, eficaz no seu resultado e, amparado pela fenomenologia, consiste em ouvir o que as pessoas vivenciam ou vivenciaram em uma situação no que se tem a dizer sobre ela quando participam de encontros, reuniões ou grupos de estudos na área acadêmica.

A História de Vida é uma dessas possibilidades metodológicas de estudo em que os participantes atribuem significados aos elementos da vida. Uma ideia que se aproxima dessa definição, está no pensamento de Glat (2004, p. 236): "Esse tipo de abordagem propicia uma aproximação maior com o sujeito ou grupo analisado, já que privilegia as apreciações das experiências de interesse interpretadas pelos próprios participantes". 
O método de História de Vida distingue-se de outras formas de investigação envolvendo depoimentos dos sujeitos envolvidos. Com a utilização de questionários ou entrevista narrativa, o pesquisador é guiado pela ação de ouvir o sujeito e dar voz a ele para que possa situar-se em relação ao problema apresentado e demonstrar possíveis soluções quando são expostos aos conceitos e ideias do método proposto. Dessa maneira, a História de Vida trabalha com história ou o relato de vida, e, narrativas demonstrando assim, a história contada porque a vivenciou.

A história de vida, ou dos depoimentos orais como recursos metodológicos de pesquisa, se ocupa em conhecer e aprofundar conhecimentos sobre determinada realidade, recuperando experiências de vida obtida através de conversas com pessoas, por meio de entrevistas que, ao focalizarem lembranças de funcionamento e das várias etapas da trajetória de um grupo social, de um sujeito da pesquisa, ponderando esses fatos pela sua importância em suas vidas. (CORREAA; GUIRAUD, 2009, p. 680).

É um método de estudos e pesquisas na área das Ciências Sociais e estabelece os limites e diferenças entre história oral, história de vida, depoimento pessoal e entrevista, situando que estas várias técnicas podem ser utilizadas na abordagem de caráter bibliográfico, como também entre autobiografia e coleta de dados como fonte de referência e pesquisa (SINSON, 1988, p. 12.).

História de Vida é um termo amplo que recobre uma quantidade de relatos a respeito de fatos não registrados por outro tipo de documentação. Colhida por meio de entrevistas de variadas formas, ela registra a experiência de um só indivíduo, de diversos indivíduos de uma mesma coletividade. Na verdade, tudo quanto se narra oralmente é história, seja a história de alguém, seja a história de um grupo, seja a história oral, seja ela mítica ou religiosa (QUEIROZ, 1987, p. 19). Sobre isso, afirma Spindola e Santos (2003, p. 121): 
Todo indivíduo tem uma história de vida e ela se revela de diversas formas, em ações, pensamentos, memórias e experiências. E todo indivíduo não está isolado em sua cotidianidade, mas inserido na mesma revelando ações que os diferem em suas características, exigindo do pesquisador distinguir as peculiaridades e especificidades do sujeito a ser pesquisado. $\mathrm{O}$ cotidiano é entendido como momento em que os atores sociais, dentro de um tempo e espaço, perfazem suas vidas e dão novos significados de desejos individuais, permitindo ao pesquisador distinguir os desafios postos através das narrativas de suas vidas, onde esses indivíduos se inserem e atuam no mundo e no grupo do qual pertence.

A história de vida se define como o relato de um narrador sobre sua existência através dos tempos, tentando reconstruir os acontecimentos que vivenciou e transmitir a experiência que adquiriu, revelando em seus depoimentos os pontos que consideram significativos, como membro de um grupo, de sua profissão, de sua camada social, de sua sociedade global, que cabe ao pesquisador desvendar (QUEIROZ, 1987, p. 20). Os sujeitos e a cultura tornam-se fundamentais para a compreensão dos vários sentidos, dos processos de comunicação e sua ligação com o cotidiano, com a memória e com as diversas práticas sociais (PERAZZO, 2015, p. 123).

Relatar histórias onde os atores educativos se encontram, envolvidos com suas ações e interpretar a partir da desses relatos, exige-se entender uma nova perspectiva de investigação educativa que põe em confronto a objetividade do conhecimento e a subjetividade interpretativa, que numa visão crítica de estudo, reconstrói as histórias de pessoas e sua prática social na busca de responder as ações pedagógicas de transformação dos sujeitos.

Esos relatos son reconstrucciones dinâmicas de las experiências, en la que sus actores dan significado a lo sucedido y vivido, mediante un processo reflexivo y por lo general recursivo. Por eso, desde esta perspectiva se puede afirmar que las narrativas estrutucturan nuestras prácticas sociales y que este 
'lenguaje de la práctica' tiende a esclarecer los propósitos de esas prácticas, haciendo que el linguaje narrativo no discurra tan sólo acerca de ellas, sino que además las constituya y colabore a producir. Pero además, la narrativa que se dedica a estudiar las prácticas narrativas de los actores legos. (SUÁREZ, 2008, p. 8).

Para esta metodologia, a coleta de dados obtidos por meio de depoimentos orais, como parte de uma história de vida se traduz, também, numa ocasião em que o entrevistado reflete sobre sua vida e também sobre sua trajetória de vida educacional. Nesse momento, percebe-se que a imagem do passado, como retorno à memória, reforça a ideia do presente, reconhecendo as ações do momento e configurando-se como entendimento dos objetivos traçados. E desde a coleta dos depoimentos, quem comanda todo o trabalho, é o próprio pesquisador, que fará de acordo com suas prerrogativas, todo levantamento possível com a temática proposta no estudo, destacando aquelas que serão relevantes para seu trabalho e desprezando aquela que não são importantes na coleta de informações.

Nessa opção metodológica, a origem do fato é sempre uma invocação à memória do sujeito, reconstruindo um passado pela perspectiva do presente, marcado pelo vivido e previsto numa perspectiva de se chegar ao conhecimento de fatos vivenciados num dado momento histórico em que dependendo somente dos documentos escritos não poderiam revelar por si só todos os sentidos presentes num determinado contexto social (CORRÊA; GUIRAUD, 2009, p. 681).

Para a área da educação, esse resgate da memória do professor, que permite ao pesquisador reconstruir histórias através dos relatos, possam subsidiar as pesquisas em suas interfaces com os diversos estudos que priorizam a formação do professor.

Geraldi (2003), trabalhando com ideia de memória do sujeito, resgata do pensamento de Bakhtin dois pilares de entendimento da subjetividade: a alteridade, que pressupõe o outro como existente e reconhecido pelo "eu" como o outro que não eu e a dialogia, pela qual se 
qualifica a relação existencial entre o eu e o outro. É claro que assumir a relação dialógica como essencial na constituição dos seres humanos não significa imaginá-la sempre em harmonia e nem desprovidas de conflitos. Em seguida, se baseando ainda no seu raciocínio em Bakhtin, a autora reforça como a memória é apresentada e explicada em relação a nossa consciência com o outro e com o mundo vivido.

No mundo dos acontecimentos da vida, campo próprio do ato ético, estamos sempre inacabados, porque definimos o presente como consequência de um passado que construiu o pré-datado e pela memória do futuro com que se definem as escolhas no horizonte das possibilidades. Nosso acabamento atende a uma necessidade estética de totalidade, e esta somente nos é dada pelo outro, como criação e não como solução. A vida concebida como acontecimento ético aberto, não comporta acabamento e, portanto, solução. (GERALDI, 2003, p. 47).

Em se tratando da História de Vida e relatos orais, o mesmo oferece um suporte metodológico aos estudos da memória e das narrativas orais, e também possibilita a compreensão de processos comunicáveis e sua intersecção com a cultura. Cada sujeito ao narrar sua trajetória de vida se revela uma testemunha viva e um artífice da história. Essas narrativas orais não são menos verdadeiras, nem menos funcionais do que muitas histórias oficiais. Não se busca puramente a verdade, pois cada sujeito narra a partir de sua subjetividade, uma vez que cada sujeito vê o objeto a partir do seu lugar no mundo (MERLEAU-PONTY, 1994), e constrói suas narrativas de forma seletiva, marcando sua trajetória de acordo com sua concepção de mundo e sua percepção de si mesmo (PERAZO, 2015).

Assim, a memória não é a história, a memória não é o vivido. A memória é o meio pelo qual nos relacionamos com o passado. As narrativas de História de Vida consideram como expressões da nossa memória são as nossas propriedades de conservar certas informações que nos remetem a "[...] um conjunto de funções próprias, graças às quais o 
homem pode atualizar impressões ou informações passadas, ou que ele representa com o passado [...]" (LE GOFF, 2013, p. 419).

Nas narrativas orais de História de Vida, fundamentadas na fenomenologia, constituem-se num método para trabalhar com o passado, com o cotidiano e com os micros experiências sociais dos sujeitos na área educacional. E também é um método que nos permite compreender como as pessoas pensam, agem, fazem e por que fizeram suas escolhas e opções de vida; posições sociais adotadas, etc. Nesse sentido, é um método que nos permite compreender as subjetividades. Dessa forma, permite trazer para as ciências as dimensões dos sentidos, dos sentimentos e das linguagens, que antes eram apenas atributos dos relatos literários e das crônicas artísticas.

Assim, os desdobramentos dos saberes e as mudanças no mundo de narrar colocando num lugar estratégico o alargamento dos modos de sentir, de pensar e de agir, possibilitando, portanto, a comunicação dessas pessoas com seu mundo (PERAZO, 2015, p. 77), ou seja, como confirma Merleau-Ponty na introdução da obra Fenomenologia da Percepção (1996), quando diz que o exercício filosófico “[...] é reaprender a ver o mundo, e nesse sentido uma história narrada pode significar o mundo com tanta 'profundidade' quanto um tratado de filosofia" (MERLAEUPONTY, 1996, p. 19). E, transpondo para a área educacional, significa fazer um exercício constante do ato filosófico, para que as ações sejam compreendidas em faces às nuances da vida profissional.

\section{Considerações Finais}

A fenomenologia traz à baila a ideia da inserção intersubjetiva entre o sujeito e o mundo, e o modo como se interligam de forma dinâmica e dialética, permitindo entender que esse pensamento filosófico tem seu caráter indissociável da filosofia da ação, ou seja, a liberdade, a intencionalidade e a consciência, se complementam através das ações da existência. Assim, a fenomenologia defende que o conhecimento é uma prática e a prática um conhecimento, a tal ponto que a verdade de uma 
filosofia não está somente no que ela diz, mas nas práticas cotidianas que ela determina. Portanto, “[...] toda filosofia é prática, mesmo aquela que parece inicialmente a mais contemplativa; o método é uma arma social e política [...]" (DARTIGUES, 2005, p. 98).

E, tratando-se da área educacional, onde os sujeitos são inseridos numa realidade social, cultural e corporal, a fenomenologia pode por meio dos seus métodos contribuírem com os estudos dos sujeitos, a partir da sua memória histórica, revelando elementos que possibilitem nova compreensão das subjetividades, através da ação do sujeito no mundo.

A fenomenologia reconhece na história os lugares dos conflitos, das ações, dos sentidos e de questionamentos da estrutura social. Por isso, ela é uma filosofia de ação e de possibilidades, pois acredita que o homem é o sujeito da história e, sendo assim, também é o sujeito das transformações nos lugares onde ele atua, vive e reflete suas ações humanas (RESENDE, 1990, p. 94).

Na perspectiva da educação, a fenomenologia introduz a noção de cultura como aquela que permite compreender melhor a existência humana como fenômeno histórico, social, concreto e transformador. Nesse sentido, “[...] a história vista numa perspectiva dialética polissêmica, aparece como um confronto entre o processo e o projeto, entre o logos e a liberdade, entre a razão e o trabalho, em suas múltiplas manifestações" (RESENDE, 1990, p. 95).

Assim, pode-se dizer que existem diversas possibilidades de ações oferecidas pela fenomenologia que podem traduzir as pesquisas na área da Educação como forma de entender o sujeito em suas interfaces de aprendizagens educacionais.

\section{Referências}

ANDRÉ, M. Formação de professores: a constituição de um campo de estudos. Educação, Porto Alegre, v. 33, n. 3, p. 174-181, set./dez. 2010. Disponível em: 
<http://revistaseletronicas.pucrs.br/ojs/index.php/faced/article/view/8075/5 719>. Acesso em: 20 out. 2018.

BRANDÃO, C. R. O que é educação. São Paulo: Editora Brasiliense, 1988.

CORRÊA, R. L. T; R. L. T; GUIRAUD, L. Possibilidades e limites de histórias de vida por meio de depoimentos orais na história da formação de professores. Revista Diálogo Educacional, Curitiba, v. 9, n. 28, p. 671686, 2009. Disponível em: <https://periodicos.pucpr.br/index.php/dialogoeducacional/article/view/33 73/3289>. Acesso em: 25 out. 2018. https://doi.org/10.7213/rde.v9i28.3373

CUNHA, A. C. T. N. et al. Elementos da fenomenologia como uma das possibilidades de compreender o jogo como um movimento humano significativo. Revista Portuguesa de Educação, Minho, v. 31, n. 2, p. 5467, 12 dez. 2018. Disponível em: <https://revistas.rcaap.pt/rpe/article/view/11714/12997>. Acesso em: 25 maio 2019. https://doi.org/10.21814/rpe.11714

DARTIGUES, A. O que é fenomenologia? São Paulo: Centauro, 2005.

FREITAS, M. T; SOUSA, S. J.; KRAMER, S. (Org.). Ciências humanas e pesquisa: Leituras de Mikhail Bakhtin. São Paulo: Cortez, 2003.

GERALDI, J. W. A diferença idêntica: a desigualdade deforma: percursos baktinianos de construção ética. In: JOBIM, M. T. F. S. \& KRAMER, S. Ciências humanas e pesquisa: Leituras de Mikhail Bakhtin. São Paulo: Cortez, 2003. p. 39-56.

GLAT, R. O método de história de vida na pesquisa em educação especial. Revista Brasileira de Educação Especial, Marília. v. 10, n. 2, p. 235-250, maio/ago. 2004.

KANT. Sobre a Pedagogia. Trad. Francisco Cock Fontanella. Piracicaba: Editora da UNIMEP, 1999. 
LE GOFF, J. História e memória. Campinas: Editora da UNICAMP, 2013.

MERLEAU-PONTY, M. Fenomenologia da percepção. São Paulo: Martins Fontes, 1994.

OLIVEIRA, M. J. S; LOPES, R. L. M.; DINIZ, N. M. F. Fenomenologia. Revista Brasileira de Enfermagem, Brasília, v. 61, n. 2, p. 254-257, 2008. Disponível em: <http://www.scielo.br/pdf/reben/v61n2/a18v61n2.pdf>. Acesso em: 25 maio 2019. https://doi.org/10.1590/S0034$\underline{71672008000200018}$

PERAZZO, P. F. Narrativas orais de história de vida. Comunicação \& Inovação, São Caetano do Sul, v. 16, n. 30, p. 121-131, jan./abr. 2015. Disponível em: <http://seer.uscs.edu.br/index.php/revista_comunicacao_inovacao/article/d ownload/2754/1672>. Acesso em: 05 nov. 2018. https://doi.org/10.13037/ci.vol16n30.2754

QUEIROZ, M. I. P. Relatos orais, do indizível ao dizível. Ciência e Cultura, São Paulo, v. 39, n. 3, p. 272-286, 1987.

REZENDE, A. M. Concepção fenomenológica da educação. São Paulo: Cortez, 1990.

SINSON, O. R. M. V. (Org.). Experimentos com histórias de vida (ItáliaBrasil). São Paulo: Vértice; Revista dos Tribunais, 1988.

SPINDOLA, T; SANTOS, R. S. Trabalhando com a história de vida: percalços de uma pesquisa(dora?). Revista da Escola de Enfermagem da USP, São Paulo, v. 37, n. 2, p. 119-126, 2003. Disponível em: <http://www.ee.usp.br/reeusp/upload/pdf/207.pdf >. Acesso em: 27 abr. 2019. https://doi.org/10.1590/S0080-62342003000200014

SUÁREZ, D. H. La documentación narrativa de experiências pedagógica, la indagación-acción del mundo escolar para la reconstrucción de la memoria pedagógica de los docentes. In: SEMINARIO DE LA RED LATINOAMERICANA DE ESTUDIOS SOBRE TRABAJO DOCENTE, 
7, 2008, Buenos Aires. Nuevas regulaciones en América Latina: anales. Buenos Aires: Universidad de Buenos Aires, 2008.

TARDIF, M. Saberes docentes e formação profissional. 7. ed. Petrópolis: Vozes, 2012.

Data de registro: $16 / 06 / 2020$

Data de aceite: $26 / 11 / 2020$ 